Research Article

\title{
Novel Intelligent Approach for Peak Shear Strength Assessment of Rock Joints on the Basis of the Relevance Vector Machine
}

\author{
Caichu Xia $\mathbb{D}^{1,2}$, Man Huang $\mathbb{D}^{1,2}$ Xin Qian $\mathbb{D}^{1},{ }^{1}$ Chenjie Hong $\mathbb{D}^{2}{ }^{2}$ Zhanyou Luo, ${ }^{3}$ \\ and Shigui $\mathrm{Du}^{2}$ \\ ${ }^{1}$ Department of Geotechnical Engineering, Tongji University, 1239 Siping Road, Shanghai 200092, China \\ ${ }^{2}$ Department of Civil Engineering, Shaoxing University, 508 Huancheng West Road, Shaoxing 312000, Zhejiang, China \\ ${ }^{3}$ Geotechnical Engineering Institute, Zhejiang University of Science and Technology, 318 Liuhe Road, Hangzhou 310023, \\ Zhejiang, China
}

Correspondence should be addressed to Man Huang; hmcadx@126.com

Received 13 July 2019; Accepted 30 November 2019; Published 19 December 2019

Academic Editor: Luis Cea

Copyright (c) 2019 Caichu Xia et al. This is an open access article distributed under the Creative Commons Attribution License, which permits unrestricted use, distribution, and reproduction in any medium, provided the original work is properly cited.

This study mainly establishes a novel intelligent assessment model for peak shear strength of rock joints based on the relevance vector machine (RVM). RVM is a state-of-the-art soft computing technique that has been rarely utilized in joint shear strength assessment. To establish the hybrid intelligent model, three-dimensional scanning tests and direct shear tests on 36 granite joint specimens were conducted. The peak shear strength ratio $\left(\tau_{p} / \sigma_{\mathrm{n}}\right)$ is perceived as an explanation of four types of influencing factors, including joint surface roughness, strength of rock material, basic friction angle, and normal stress. In particular, the compressive strength and tensile strength of rock material are first considered together. A total of 36 experimental data were used in this study to train the RVM model to predict the peak shear strength of rock joints. The performance of the RVM model was assessed using the direct shear test data of rock joints collected from previous researches. Four different kinds of kernel functions were adopted to obtain the optimal model. Results show that the proposed model is significantly efficient in predicting the peak shear strength of rock joints. The proposed model is also a promising tool for peak shear strength of rock joints and provides a new research approach to research the mechanical properties of rock joints.

\section{Introduction}

The deformation capacity, strength, and stability of fractured rock mass are strongly influenced by the shear behavior of joints. Therefore, the accurate determination of shear strength is the key to design the safety structure in rock mass or rock masses [1]. Over the past decades, empirical [2-9], semi-theoretical [10], and theoretical methods [11] have been proposed to determine the shear strength of rock joints. Various factors, such as rock type, joint surface roughness, joint size, and infilling materials, exhibit a wide variation of joint shear strength $[12,13]$. Considering their strong randomness, fuzziness, and uncertainty, the peak shear strength of rock joints has a complex nonlinear relationship with the aforementioned factors $[14,15]$. The traditional methods demonstrate strong usability and dependability in practical engineering, but large computations and complex algorithms limit the use of these methods. Thus, the deterministic analysis methods in assessing the joint shear strength remain difficult. In recent years, data mining and artificial intelligence technologies, such as artificial neural network (ANN) and support vector machine (SVM), have been widely used to estimate the mechanical properties of rocks, such as the compressive strength and tensile strength [16-21]. However, ANN has several disadvantages, such as poor generalizing performance, large training data requirement, slow convergence velocity, and over-fitting problem [22-24]. SVM can effectively solve the aforementioned problems and exhibit excellent generalization capability and high regression accuracy $[25,26]$. Despite many advantages, SVM suffers from several limitations. The output of an SVM represents decisions rather than posterior 
probabilities [27]. In addition, the kernel function of SVM must fulfill Mercer's condition. The relevance vector machine (RVM) is a probabilistic model based on Bayesian theory for regression and classification; it has high generalization capability, sparse model structure, and low computation complexity, avoiding the principal limitations of SVM [28]. Especially for small samples, RVM can map the limited input data into a high-dimensional feature space and finally use several relevance vectors to deal with the dimensionality problems. The primary purpose of this study is to introduce a reliable estimation method of peak shear strength of rock joints on the basis of RVM. To this end, 36 rock joints under different stress were designed and tested in laboratory. The rest of this article is organized as follows: Section 2 presents the theoretical background of RVM. Section 3 introduces the description of the experimental procedure and results. Section 4 describes the establishment of the RVM model. Section 5 presents the comparison and discussion. The final section presents the conclusions.

\section{RVM Method}

RVM is a probabilistic learning model based on the Bayesian framework to solve complex regression and classification problems [28]. It generates a mapping between the targets $\left\{t_{n}\right\}_{n=1}^{N}$ and the corresponding input vectors $\left\{x_{n}\right\}_{n=1}^{N}$.

$$
t_{n}=y\left(x_{n} ; \omega\right)+\varepsilon_{n}=\sum_{n=1}^{N} \omega_{n} K\left(x, x_{n}\right)+\omega_{0}+\varepsilon_{n},
$$

where $N$ is the total sample number, $n$ is the $n$th sample number, $y$ is the output variable, $\omega_{n}$ is the weight of the $n$th sample, $K\left(x, x_{n}\right)$ is the kernel functions, and $\varepsilon_{n}$ is a meanzero white noise process with variance $\sigma^{2}$.

Assuming an independent distribution for $t_{n}$, the likelihood of the entire dataset can be expressed as follows:

$$
p\left(\mathbf{t} \mid \boldsymbol{\omega}, \sigma^{2}\right)=\left(2 \pi \sigma^{2}\right)^{-N / 2} \exp \left(-\frac{\|\mathbf{t}-\boldsymbol{\Phi} \boldsymbol{\omega}\|^{2}}{2 \sigma^{2}}\right)
$$

where $\mathbf{t}=\left\{t_{1}, t_{2}, \ldots, t_{N}\right\}^{\mathrm{T}}, \quad \boldsymbol{\omega}=\left\{\omega_{0}, \omega_{1}, \ldots, \omega_{N}\right\}^{\mathrm{T}}, \quad$ and $\boldsymbol{\Phi}\left(x_{n}\right)=\left\{1, K\left(x_{n}, x_{1}\right), \ldots, K\left(x_{n}, x_{N}\right)\right\}^{\mathrm{T}}$.

Direct maximum-likelihood estimation of $\omega$ from equation (2) may suffer from overfitting [29]. Therefore, a zero-mean Gaussian prior distribution over every weight $\omega_{i}$ with the diagonal covariance $\alpha$ is adopted and described as follows:

$$
p(\omega \mid \alpha)=\prod_{i=0}^{N} N\left(\omega_{i} \mid 0, \alpha_{i}^{-1}\right) .
$$

The posterior distribution for the weights can then be calculated using Bayes' law based on the Gamma prior distributions [30]:

$$
p\left(\omega \mid t, \alpha, \sigma^{2}\right)=\frac{p\left(t \mid \omega, \sigma^{2}\right) p(\omega \mid \alpha)}{p\left(t \mid \alpha, \sigma^{2}\right)} .
$$

Integrating the weight parameters, the marginal distribution of hyperparameters $\alpha$ and $\sigma^{2}$ can be obtained:

$$
p\left(t \mid \alpha, \sigma^{2}\right)=(2 \pi)^{-N / 2}|\Omega| \exp \left(\frac{-t^{\mathrm{T}} \Omega^{-1} t}{2}\right)
$$

where $\Omega=\sigma^{2} E+\Phi A^{-1} \Phi^{\mathrm{T}}, A=\operatorname{diag}\left(\alpha_{0}, \alpha_{1}, \ldots, \alpha_{N}\right)$, and $E$ is a unit vector. Taking its partial derivatives to equation (5) by iteration, the values of $\alpha$ and $\sigma^{2}$ can be obtained.

\section{Experimental Procedure and Results}

3.1. Preparation of Rock Samples. To investigate the effect of wide-range normal stress on peak shear strength, rectangular granite joints were selected for the direct shear tests because of their high strength. Rectangular blocks of rock specimens with dimension of $100 \mathrm{~mm} \times 100 \mathrm{~mm} \times 200 \mathrm{~mm}$ were labeled as SJ1-SJ36. Brazilian splitting tests were conducted by using a TSF-600 shear-flow coupled test system for rock joints at Tongji University. The granite joint surface dimensions were approximately $100 \mathrm{~mm}$ wide and $200 \mathrm{~mm}$ long (Figure 1). After testing, no apparent defects were found in the specimens. $\sigma_{c}$ is the uniaxial compressive strength, $\sigma_{\mathrm{t}}$ is the tensile strength, $E$ is Young's modulus, $\rho$ is the rock density, and $\gamma$ is Poisson's ratio, and basic friction angle $\varphi_{\mathrm{b}}$ was determined using the suggested methods of the International Society for Rock Mechanics (ISRM) [31], and the results are listed in Table 1.

3.2. Surface Topography Measurement. To investigate the influence of the three-dimensional (3D) surface roughness on the mechanical properties of rock joints quantitatively, the joint surface topography of measuring each shear test sample block before using a noncontact direct shear test, 3D stereo-topometric measurement system (positioning accuracy: $20 \mu \mathrm{m}$ ) was developed by Xia et al. [32]. Before the estimation of joint surface roughness, the $3 \mathrm{D}$ surface topography was reconstructed on the basis of the interpolation of the scanned point clouds. Tatone and Grasselli indicated that the digitized surface topographies of rock joints with sampling interval $<0.55 \mathrm{~mm}$ using linear interpolation technique can capture microfeatures of surface morphology [33]. In this study, we set the sampling intervals in length $(L)$ and width $(W)$ directions to be $0.3 \mathrm{~mm}$. Taking upper surface topographies of four joint samples as examples, the digitized surface topographies of rock joints (the height magnified to 3 times its normal size) are shown in Figure 2.

3.3. Test Procedure and Results. This test was designed to obtain an extensive peak shear strength model of rock joints. We conduct the direct shear tests on the test samples under nine normal stress levels, namely, 1.0, 2.0, 3.0, 5.0, 8.0, 10.0, 12.0, 15.0, and 20.0 MPa. Four direct tests were performed on the test specimen at each level of normal stress. The values of the peak shear strength for each test specimen are listed in Table 2. The rate of shear displacement was set to be $0.5 \mathrm{~mm} /$ min, and the maximum displacement was $20 \mathrm{~mm}$ which is $10 \%$ of the joint length. 


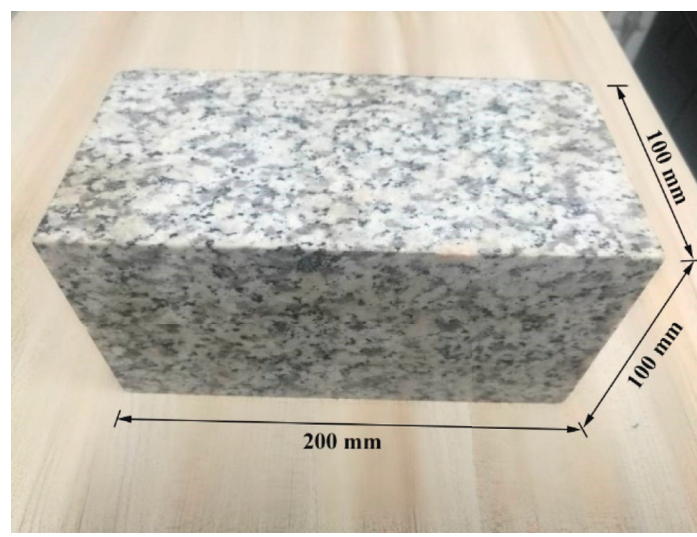

(a)

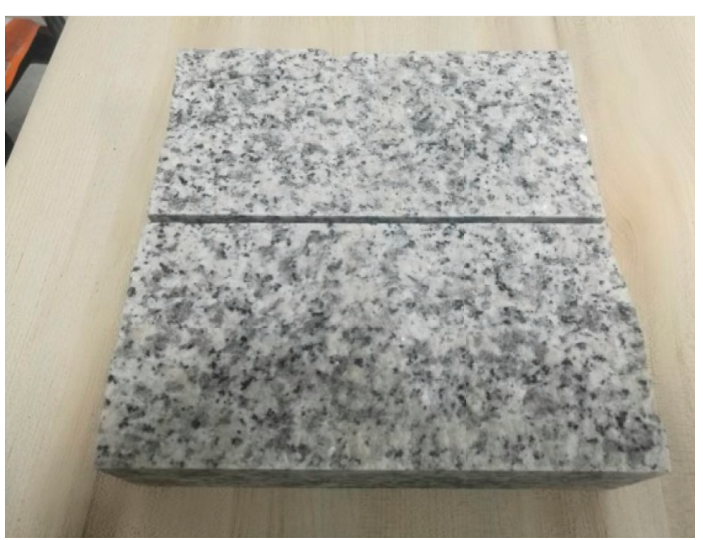

(b)

FIgURE 1: Granite block and granite joint specimen.

TABLE 1: Physical and mechanical parameters of granite rock.

\begin{tabular}{lccccc}
\hline$\sigma_{\mathrm{c}}(\mathrm{MPa})$ & $\sigma_{\mathrm{t}}(\mathrm{MPa})$ & $E(\mathrm{GPa})$ & $\mathrm{P}\left(\mathrm{g} / \mathrm{cm}^{3}\right)$ & $\gamma$ & $\varphi_{\mathrm{b}}$ \\
\hline 161.0 & 10.8 & 45.5 & 2.64 & 0.23 & $33.28^{\circ}$ \\
\hline
\end{tabular}

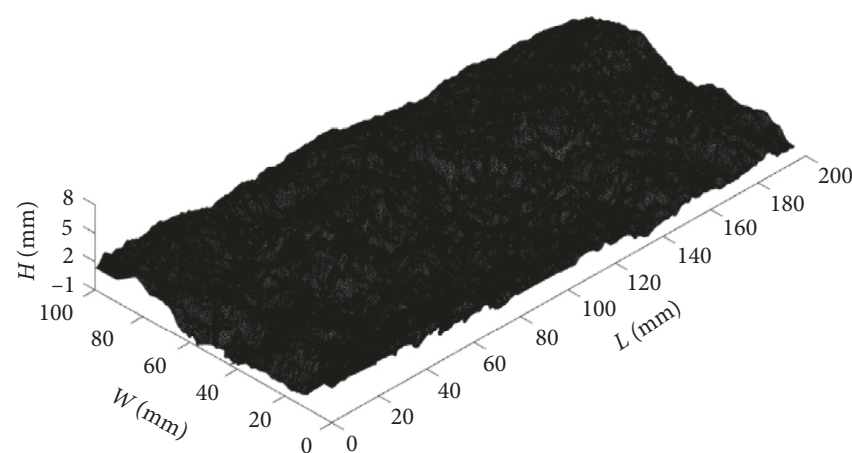

(a)

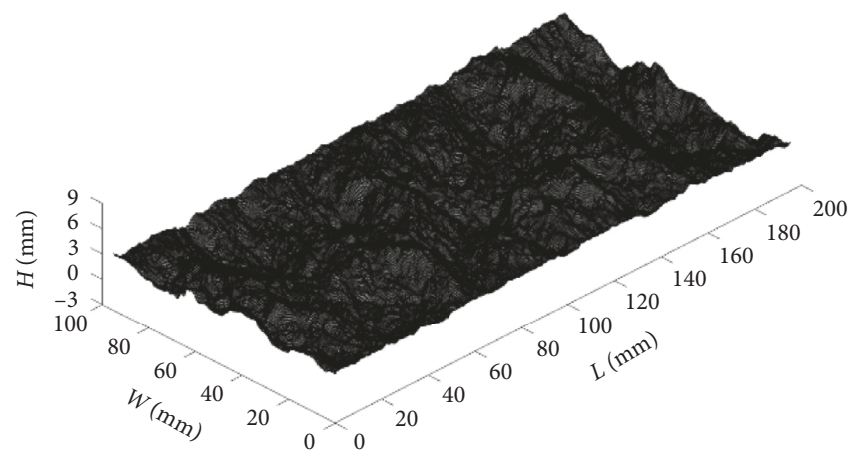

(c)

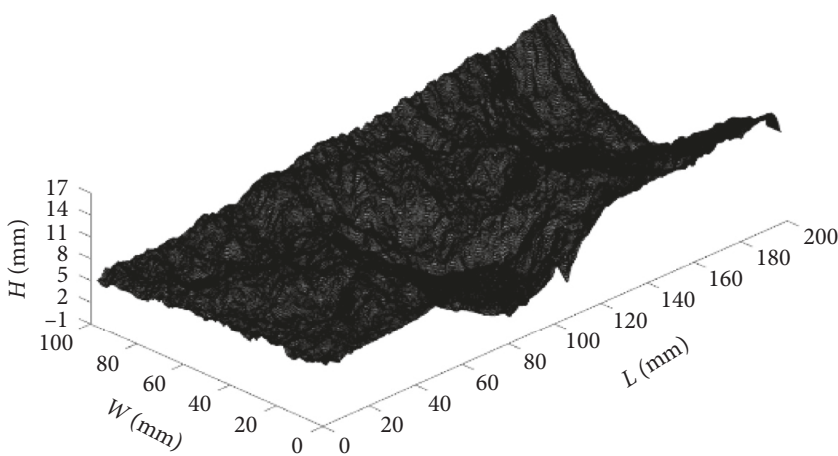

(b)

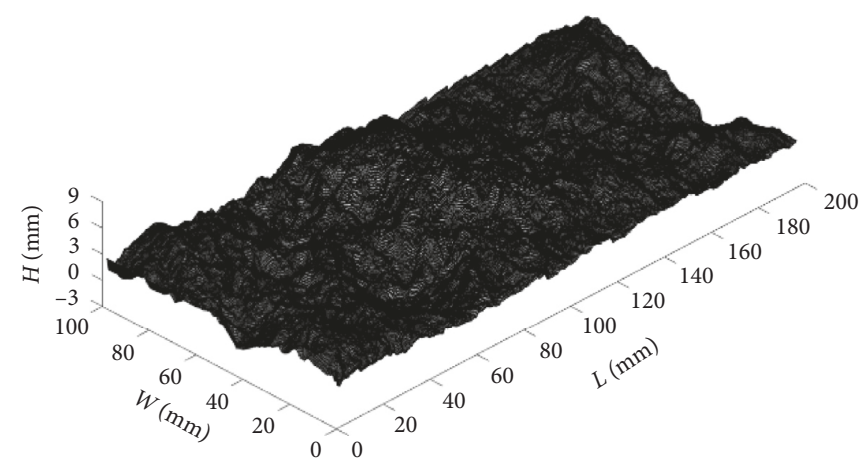

(d)

Figure 2: 3D digitized upper surface topographies of rock joints: (a) SJ3, (b) SJ12, (c) SJ21, and (d) SJ30.

\section{Establishment of a Peak Shear Strength Assessment Model Based on RVM}

4.1. Selecting the Influencing Factors. According to the study by Barton and Choubey [34], the joint surface roughness, rock material strength, basic friction angle, and normal stress exhibit a wide variation of shear behavior. Therefore, normal stress, joint surface roughness, rock strength, and basic friction angle were selected in this work to assess the peak shear strength.

Various parameters, including empirical, statistical, and fractal, have been proposed to quantify the surface roughness of rock joints. Numerous experimental tests demonstrated that partial contact between the lower and upper joint surface was located in the steepest zones facing the 
TABle 2: Peak shear strength of test specimens.

\begin{tabular}{|c|c|c|}
\hline Sample name & $\sigma_{\mathrm{n}}(\mathrm{MPa})$ & $\tau_{p}(\mathrm{MPa})$ \\
\hline SJ1 & 1 & 2.30 \\
\hline SJ2 & 2 & 4.55 \\
\hline SJ3 & 3 & 4.78 \\
\hline SJ4 & 5 & 8.30 \\
\hline SJ5 & 8 & 9.63 \\
\hline SJ6 & 10 & 12.75 \\
\hline SJ7 & 12 & 13.64 \\
\hline SJ8 & 15 & 17.28 \\
\hline SJ9 & 20 & 21.26 \\
\hline SJ10 & 1 & 1.89 \\
\hline SJ11 & 2 & 3.64 \\
\hline SJ12 & 3 & 7.41 \\
\hline SJ13 & 5 & 8.28 \\
\hline SJ14 & 8 & 11.15 \\
\hline SJ15 & 10 & 13.23 \\
\hline SJ16 & 12 & 14.61 \\
\hline SJ17 & 15 & 18.07 \\
\hline SJ18 & 20 & 19.76 \\
\hline SJ19 & 1 & 3.07 \\
\hline SJ20 & 2 & 3.65 \\
\hline SJ21 & 3 & 5.46 \\
\hline SJ22 & 5 & 7.05 \\
\hline SJ23 & 8 & 11.92 \\
\hline SJ24 & 10 & 12.57 \\
\hline SJ25 & 12 & 14.49 \\
\hline SJ26 & 15 & 16.15 \\
\hline SJ27 & 20 & 20.99 \\
\hline SJ28 & 1 & 2.49 \\
\hline SJ29 & 2 & 5.21 \\
\hline SJ30 & 3 & 5.29 \\
\hline SJ31 & 5 & 7.70 \\
\hline SJ32 & 8 & 13.18 \\
\hline SJ33 & 10 & 12.23 \\
\hline SJ34 & 12 & 15.44 \\
\hline SJ35 & 15 & 17.74 \\
\hline SJ36 & 20 & 24.91 \\
\hline
\end{tabular}

shear direction during the shearing [35-37]. Grasselli et al. [38] established a relationship between total potential contact area ratio $A_{\theta^{*}}$ and the corresponding apparent dip angle $\theta^{*}$, as shown in the following equation:

$$
A_{\theta^{*}}=A_{0}\left[\frac{\theta_{\max }^{*}-\theta^{*}}{\theta_{\max }^{*}}\right]^{C},
$$

where $A_{0}$ is the maximum potential contact area under apparent dip angle $\theta^{*}$ at $0^{\circ} ; \theta_{\max }^{*}$ is the maximum apparent dip angle in the shear direction; and $C$ is a dimensionless roughness parameter characterizing the distribution of the apparent dip angle over the surface, which is calculated using equation (6). Considering the possible range of $C \in(0, \infty)$, the surface roughness of rock joints can be measured by the roughness metric $\theta_{\max }^{*} /(C+1)$ [33]. $A_{0}$ varies significantly in different directions; thus, the $3 \mathrm{D}$ roughness metric $A_{0}$ and $\theta_{\max }^{*} /(C+1)$ are both included to fully describe the roughness anisotropy. The 3D morphology parameters of the granite joints, namely, $A_{0}, \theta_{\max }^{*}$, and $C$, were calculated using the measured data from 36 surfaces on the basis of equation (6). The values of $A_{0}$ and $\theta_{\max }^{*} /(C+1)$ are listed in Table 3 .
TABLE 3: 3D morphology parameters of test specimens.

\begin{tabular}{|c|c|c|}
\hline Sample name & $A_{0}$ & $\theta_{\max }^{*} /(C+1)(\mathrm{deg})$ \\
\hline SJ1 & 0.479 & 10.465 \\
\hline SJ2 & 0.498 & 12.433 \\
\hline SJ3 & 0.504 & 10.139 \\
\hline SJ4 & 0.510 & 12.384 \\
\hline SJ5 & 0.467 & 10.870 \\
\hline SJ6 & 0.477 & 12.718 \\
\hline SJ7 & 0.542 & 10.237 \\
\hline SJ8 & 0.504 & 10.197 \\
\hline SJ9 & 0.472 & 10.208 \\
\hline SJ10 & 0.502 & 9.952 \\
\hline SJ11 & 0.484 & 11.961 \\
\hline SJ12 & 0.498 & 14.253 \\
\hline SJ13 & 0.528 & 14.405 \\
\hline SJ14 & 0.520 & 11.266 \\
\hline SJ15 & 0.498 & 10.411 \\
\hline SJ16 & 0.508 & 10.659 \\
\hline SJ17 & 0.501 & 11.699 \\
\hline SJ18 & 0.485 & 11.298 \\
\hline SJ19 & 0.496 & 12.499 \\
\hline SJ20 & 0.481 & 10.708 \\
\hline SJ21 & 0.505 & 12.808 \\
\hline SJ22 & 0.532 & 12.134 \\
\hline SJ23 & 0.471 & 14.002 \\
\hline SJ24 & 0.505 & 11.191 \\
\hline SJ25 & 0.499 & 11.398 \\
\hline SJ26 & 0.495 & 10.365 \\
\hline SJ27 & 0.433 & 10.083 \\
\hline SJ28 & 0.493 & 11.231 \\
\hline SJ29 & 0.498 & 13.550 \\
\hline SJ30 & 0.501 & 10.829 \\
\hline SJ31 & 0.512 & 11.177 \\
\hline SJ32 & 0.502 & 11.975 \\
\hline SJ33 & 0.454 & 10.467 \\
\hline SJ34 & 0.479 & 12.858 \\
\hline SJ35 & 0.492 & 9.942 \\
\hline SJ36 & 0.514 & 15.303 \\
\hline
\end{tabular}

Figure 3 shows the fitting curves of SJ3, SJ12, SJ21, and SJ36 for calculating the roughness parameter $C$.

Joint wall compressive strength (JCS) is commonly used for representing the influence of rock material strength on the shear behavior of rock joints $[3,8,25,39-41]$. For the fresh rock, JCS can be replaced by the uniaxial compressive strength $\sigma_{\mathrm{c}}$. Based on experimental observation and numerical simulations, several researchers have also found that the failure of asperities in rock joints under direct shear loading was possibly attributed to shear-induced tensile fracture $[5,6,42-44]$. However, the failure mechanism of asperities has not been clearly stated, and controversies still exist. Therefore, uniaxial compressive strength $\sigma_{\mathrm{c}}$ and tensile strength $\sigma_{\mathrm{t}}$ of the rock are both selected in this study to describe the effect of rock material strength on the peak shear strength of rock joints.

Basic friction angle $\varphi_{\mathrm{b}}$ is crucial to determine the shear strength of rock joints. Barton suggested a fundamental form of joint shear strength [3]:

$$
\tau_{p}=\sigma_{\mathrm{n}} \tan \left[\varphi_{\mathrm{b}}+d_{n}+s_{n}\right]
$$




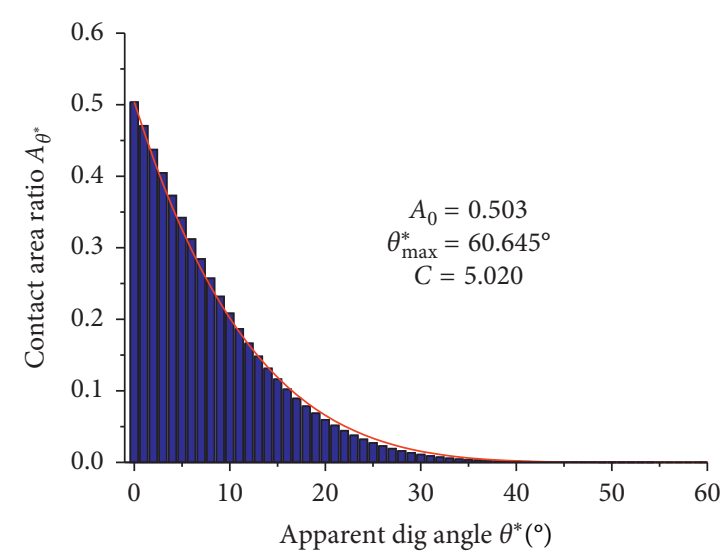

(a)

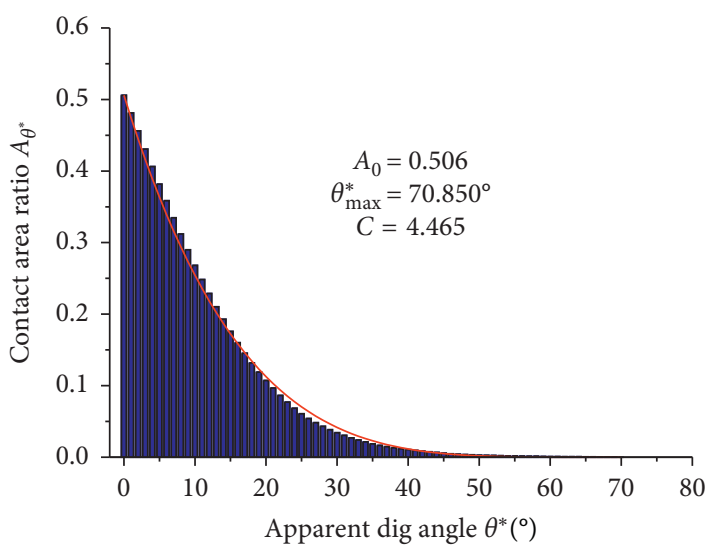

(c)

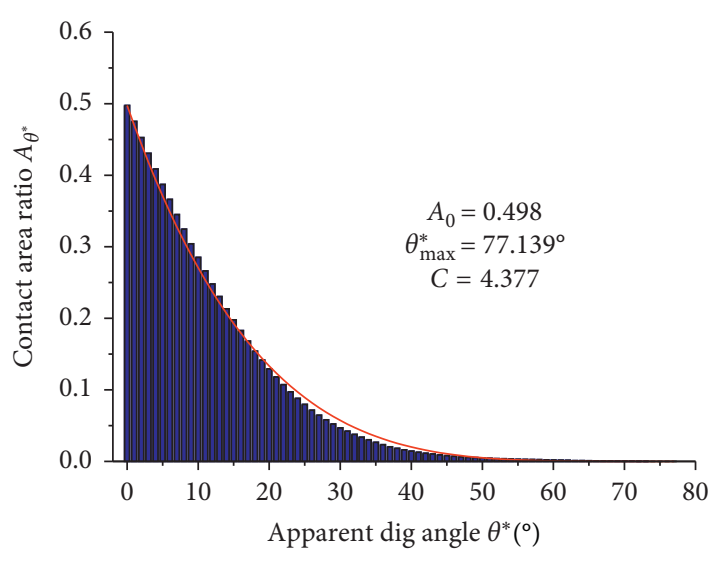

(b)

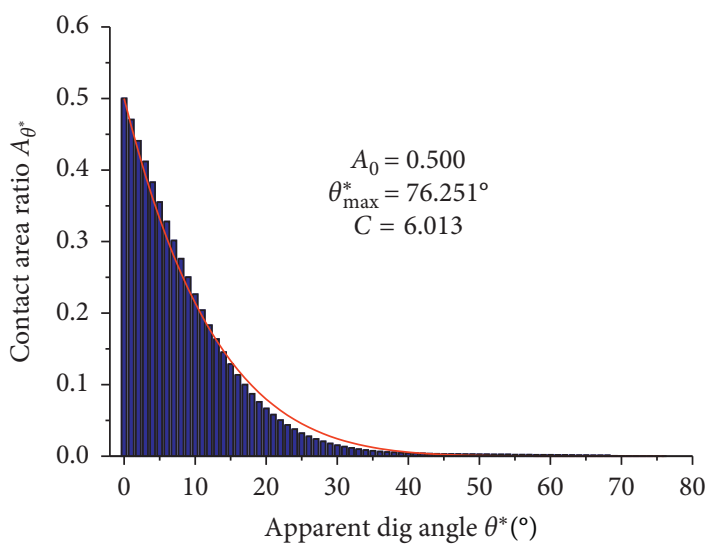

(d)

FIGURE 3: Fitting results of the contact area ratio and apparent dip angle by equation (6): (a) SJ3, (b) SJ12, (c) SJ21, and (d) SJ30.

where $\sigma_{\mathrm{n}}$ is the normal stress, $d_{n}$ is the peak dilation angle, and $s_{n}$ is the shear component angle. On the basis of equation (7), various 2D or 3D morphology parameters have been used for representing the sum of peak dilation angle $d_{n}$ and shear component angle $s_{n}$. No uniform approach for obtaining the basic angle $\varphi_{\mathrm{b}}$ is currently available. In this work, laboratory direct shear testing method for two smooth joint surfaces is adopted to obtain the basic angle $\varphi_{\mathrm{b}}$ and the extensive shear strength model, as shown in Table 1.

4.2. Training and Testing of the RVM Model. In this study, the aforementioned original influencing factors, namely, $\sigma_{n}$, $\sigma_{\mathrm{c}}$, and $\sigma_{\mathrm{t}}$, can be dimensionless preprocessed as two factors: $\mathrm{JCS} / \sigma_{\mathrm{n}}$ and $\sigma_{\mathrm{n}} / \sigma_{\mathrm{t}}$. Therefore, the five influencing factors, which include JCS $/ \sigma_{\mathrm{n}}, \sigma_{\mathrm{n}} / \sigma_{\mathrm{t}}, A_{0}, \theta_{\max }^{*} /(C+1)$, and $\varphi_{\mathrm{b}}$, form the input vector of the regression model. All these index values can be measured in the laboratory (see Tables 1-3). Mapping the above five influencing factors to the five-dimensional feature space according to the definition of RVM, the appropriate kernel function was chosen to simplify the nonlinear transformation. The linear kernel function was first used due to its parameter-free and rapid calculation as follows:

$$
K(x, z)=\langle x, z\rangle,
$$

where $\langle x, z\rangle$ are the training dataset of five influencing factors. The results of direct shear tests on 36 rocks in this study were used to cultivate and advance the RVM model. The results of direct shear tests by Grasselli and Egger [5] and Yang et al. [8] were used for testing the RVM model, in which a total of 50 tests were conducted on five different material types of rock joints (granite, sandstone, limestone, marble, and serpentinite). The 3D morphology parameters of 50 groups of rock joints are represented in Table 4. After the analysis was completed, the quality of the regression model was estimated by the average error formula and correlation coefficient [45]:

$$
\begin{aligned}
\bar{\sigma}_{\text {avg }}= & \frac{1}{n} \sum_{i=1}^{n}\left|\frac{\tau_{\text {mea }}-\tau_{\text {est }}}{\tau_{\text {mea }}}\right| \times 100 \%, \\
\text { Fitness } \_\bar{\sigma}_{\text {avg }}= & \frac{\operatorname{train} \_\bar{\sigma}_{\text {avg }} \cdot \operatorname{train} \_n+\text { test } \_\bar{\sigma}_{\text {avg }} \cdot \text { test } \_n}{\operatorname{train} \_n+\text { test } \_n}, \\
R^{2} & =1-\frac{\sum_{i=1}^{n}\left(\tau_{\text {est }}-\tau_{\text {mea }}\right)^{2}}{\sum_{i=1}^{n}\left(\tau_{\text {est }}-\overline{\tau_{\text {mea }}}\right)^{2}}, \\
\text { Fitness } \_R^{2} & =\frac{\text { train } \_R^{2} \cdot \operatorname{train} \_n+\text { test } \_R^{2} \cdot \text { test } \_n}{\operatorname{train} \_n+\text { test } \_n},
\end{aligned}
$$


TABLE 4: Comparison between the measured peak shear strength and the calculated results by three different models.

\begin{tabular}{|c|c|c|c|c|c|c|c|c|c|}
\hline \multirow{2}{*}{ Sample name } & \multirow{2}{*}{$\mathrm{JCS} / \sigma_{\mathrm{n}}$} & \multirow{2}{*}{$\sigma_{\mathrm{n}} / \sigma_{\mathrm{t}}$} & \multirow{2}{*}{$\theta_{\max }^{*} /(C+1)(\mathrm{deg})$} & \multirow{2}{*}{$A_{0}$} & \multirow{2}{*}{$\varphi_{\mathrm{b}}(\mathrm{deg})$} & \multicolumn{4}{|c|}{ Peak shear strength $(\mathrm{MPa})$} \\
\hline & & & & & & Measured & Grasselli & Yang & Proposed \\
\hline$\overline{\mathrm{G} 1}$ & 81.2 & 0.26 & 11.016 & 0.493 & 34 & 5.7 & 4.6 & 6.0 & 4.8 \\
\hline G2 & 81.2 & 0.26 & 12.121 & 0.498 & 34 & 5.6 & 5.1 & 6.0 & 4.8 \\
\hline G4 & 85.2 & 0.25 & 10.031 & 0.498 & 34 & 4.8 & 4.3 & 4.3 & 4.6 \\
\hline G5 & 166.7 & 0.13 & 9.005 & 0.46 & 34 & 2.4 & 2.3 & 2.0 & 2.7 \\
\hline G6 & 166.7 & 0.13 & 10.012 & 0.477 & 34 & 2.9 & 2.4 & 2.7 & 2.7 \\
\hline G7 & 166.7 & 0.13 & 9.939 & 0.47 & 34 & 2.8 & 2.4 & 2.6 & 2.7 \\
\hline G9 & 166.7 & 0.13 & 10.949 & 0.508 & 34 & 3.0 & 2.6 & 2.6 & 2.7 \\
\hline $\mathrm{C} 1$ & 23.3 & 0.45 & 9.963 & 0.491 & 36 & 2.2 & 1.9 & 2.2 & 1.7 \\
\hline C2 & 23.3 & 0.45 & 12.048 & 0.462 & 36 & 2.1 & 2.2 & 2.6 & 1.8 \\
\hline C3 & 6.7 & 1.55 & 10.179 & 0.46 & 36 & 5.5 & 5.5 & 5.1 & 4.8 \\
\hline $\mathrm{C} 4$ & 10.2 & 1.02 & 11.324 & 0.508 & 36 & 4.6 & 4.1 & 4.2 & 3.3 \\
\hline C5 & 8.1 & 1.30 & 11.821 & 0.495 & 36 & 5.0 & 5.2 & 5.1 & 4.1 \\
\hline C6 & 24.4 & 0.43 & 10.985 & 0.546 & 36 & 2.1 & 2.1 & 2.1 & 1.7 \\
\hline C8 & 8.1 & 1.30 & 11.028 & 0.555 & 36 & 4.9 & 4.9 & 4.8 & 4.1 \\
\hline M1 & 100.0 & 0.09 & 7.143 & 0.513 & 37 & 1.7 & 1.8 & 1.7 & 2.1 \\
\hline M2 & 50.0 & 0.19 & 5.909 & 0.492 & 37 & 2.3 & 3.2 & 2.4 & 3.8 \\
\hline M3 & 100.0 & 0.09 & 5.652 & 0.471 & 37 & 1.2 & 1.7 & 1.4 & 2.1 \\
\hline M4 & 23.3 & 0.41 & 6.689 & 0.513 & 37 & 5.8 & 6.3 & 5.7 & 6.3 \\
\hline M5 & 33.3 & 0.28 & 5.948 & 0.533 & 37 & 4.4 & 4.6 & 3.8 & 4.9 \\
\hline M6 & 33.3 & 0.28 & 6.082 & 0.45 & 37 & 4.3 & 4.4 & 4.0 & 4.9 \\
\hline M7 & 23.3 & 0.41 & 6.001 & 0.502 & 37 & 5.6 & 6.1 & 5.8 & 6.2 \\
\hline M8 & 22.7 & 0.42 & 6.250 & 0.459 & 37 & 6.4 & 6.1 & 5.7 & 6.3 \\
\hline M9 & 33.3 & 0.28 & 5.194 & 0.494 & 37 & 4.5 & 4.4 & 3.6 & 4.9 \\
\hline M10 & 100.0 & 0.09 & 5.683 & 0.515 & 37 & 1.5 & 1.7 & 1.4 & 2.1 \\
\hline M12 & 47.6 & 0.09 & 6.643 & 0.429 & 37 & 3.0 & 3.6 & 2.8 & 3.8 \\
\hline ML1 & 9.8 & 1.46 & 8.000 & 0.573 & 37 & 1.4 & 1.3 & 1.4 & 1.4 \\
\hline ML2 & 2.4 & 5.90 & 6.988 & 0.505 & 37 & 4.5 & 4.8 & 3.7 & 5.1 \\
\hline ML3 & 4.8 & 2.99 & 7.491 & 0.523 & 37 & 2.3 & 4.7 & 2.2 & 2.7 \\
\hline S1 & 83.3 & 0.32 & 13.621 & 0.504 & 39 & 4.3 & 6.0 & 8.1 & 5.2 \\
\hline S2 & 166.7 & 0.16 & 13.787 & 0.466 & 39 & 3.4 & 1.9 & 4.1 & 3.1 \\
\hline Granite (G3) & 201.3 & 0.09 & 7.075 & 0.61 & 34 & 1.5 & 1.5 & 1.5 & 1.3 \\
\hline Granite (G4) & 100.6 & 0.18 & 7.535 & 0.53 & 34 & 3.1 & 2.9 & 3.0 & 3.4 \\
\hline Granite (G5) & 67.1 & 0.27 & 7.551 & 0.48 & 34 & 4.8 & 4.0 & 4.4 & 4.9 \\
\hline Granite (G6) & 50.3 & 0.36 & 7.982 & 0.51 & 34 & 5.8 & 5.2 & 5.8 & 6.1 \\
\hline Granite (G7) & 40.3 & 0.45 & 6.952 & 0.47 & 34 & 6.4 & 5.8 & 6.4 & 7.1 \\
\hline Granite (G8) & 33.5 & 0.55 & 6.902 & 0.49 & 34 & 7.3 & 6.7 & 7.5 & 7.9 \\
\hline Granite (G9) & 28.8 & 0.64 & 6.661 & 0.53 & 34 & 8.5 & 7.6 & 8.3 & 8.7 \\
\hline Granite (G10) & 25.2 & 0.73 & 7.959 & 0.56 & 34 & 11.0 & 8.8 & 10.5 & 9.6 \\
\hline Granite (G11) & 22.4 & 0.82 & 7.784 & 0.51 & 34 & 11.2 & 9.3 & 11.2 & 10.4 \\
\hline Granite (G12) & 20.1 & 0.91 & 8.842 & 0.53 & 34 & 12.7 & 10.6 & 13.3 & 11.2 \\
\hline Sandstone (S3) & 200.0 & 0.13 & 8.459 & 0.51 & 28 & 0.7 & 0.5 & 0.5 & 0.4 \\
\hline Sandstone (S4) & 100.0 & 0.25 & 9.555 & 0.61 & 28 & 0.9 & 1.0 & 1.1 & 1.1 \\
\hline Sandstone (S5) & 66.7 & 0.38 & 8.797 & 0.54 & 28 & 1.5 & 1.3 & 1.5 & 1.6 \\
\hline Sandstone (S6) & 50.0 & 0.50 & 8.453 & 0.49 & 28 & 2.0 & 1.6 & 1.9 & 2.0 \\
\hline Sandstone (S7) & 40.0 & 0.63 & 7.863 & 0.55 & 28 & 2.1 & 1.9 & 2.3 & 2.3 \\
\hline Sandstone (S8) & 33.3 & 0.75 & 9.150 & 0.58 & 28 & 3.0 & 2.3 & 2.9 & 2.6 \\
\hline Sandstone (S9) & 28.6 & 0.88 & 8.344 & 0.5 & 28 & 3.3 & 2.4 & 3.1 & 2.9 \\
\hline Sandstone (S10) & 25.0 & 1.00 & 8.489 & 0.47 & 28 & 3.6 & 2.6 & 3.5 & 3.2 \\
\hline Sandstone (S11) & 22.2 & 1.13 & 8.116 & 0.44 & 28 & 3.8 & 2.8 & 3.8 & 3.5 \\
\hline Sandstone (S12) & 20.0 & 1.25 & 9.016 & 0.51 & 28 & 4.7 & 3.3 & 4.4 & 3.7 \\
\hline
\end{tabular}

where $\bar{\sigma}_{\text {avg }}$ is the average estimation error, $n$ is the sample size, $\tau_{\text {mea }}$ is the measured peak shear strength, $\tau_{\text {est }}$ is the estimated peak shear strength, $\overline{\tau_{\text {mea }}}$ is the average value of the measured peak shear strength, Fitness $\bar{\sigma}_{\text {avg }}$ is the comprehensive estimation error of the RVM model, and Fitness_ $R^{2}$ is the correlation coefficient of the train and test model; train $n$ is the number of the training sample, and test_ $n$ is the number of the testing sample. In this work, train_n and test_ $n$ are 36 and 50, respectively. The average estimation errors of the RVM model for the training and testing data are $6.46 \%$ and $21.12 \%$, respectively. The correlation coefficient of the RVM model for the training and testing data is 0.977 and 0.769 , respectively. The comprehensive estimation error Fitness_ $\bar{\sigma}_{\text {avg }}$ and correlation coefficient Fitness_ $R^{2}$ of the 
RVM model for all the data are $14.98 \%$ and 0.856 , respectively. This finding indicates that the RVM model exhibits good training accuracy and high generalization capacity. Therefore, the RVM model is feasible and effective for estimating the peak shear strength of rock joints and can be used in practical applications.

\section{Comparison and Discussion}

5.1. RVM with Different Kernel Functions. The inner product of kernel functions is usually substituted for the complex calculation of high-dimensional feature space to deal with the dimensionality problem under high-dimensional feature space. The nonlinear shining mode from the raw feature space to high-dimensional space relays on the type of kernel functions. The approximate kernel function and model parameters have a considerable effect on the model stability and regression precision [46].

To further enhance the accuracy of the proposed model, three other common kernel functions were introduced: polynomial kernel function, Gaussian kernel function, and sigmoid kernel function.

Polynomial kernel function: $K(x, z)=(a \cdot\langle x, z\rangle+b)^{c}$,

Gaussian kernel function: $K(x, z)=\exp \left(\frac{-\|x-z\|^{2}}{2 d^{2}}\right)$,

Sigmoid kernel function: $K(x, z)=\tanh (k \cdot\langle x, z\rangle+p)$,
TABLE 5: Kernel function parameters and average estimation errors.

\begin{tabular}{lccc}
\hline $\begin{array}{l}\text { Kernel } \\
\text { function type }\end{array}$ & Fitness_ $\bar{\sigma}_{\text {avg }}(\%)$ & Fitness_ $R^{2}$ & Parameter number \\
\hline Linear & 14.98 & 0.856 & 0 \\
Polynomial & 12.41 & 0.957 & 3 \\
Gaussian & 12.24 & 0.956 & 1 \\
Sigmoid & 13.44 & 0.952 & 2 \\
\hline
\end{tabular}

where $a, b, c, d, k$, and $p$ are kernel function parameters.

In the RVM model, the kernel function parameters must be defined. The most relevant papers which include the determination of the optimal kernel function parameters for RVM is lacking. Several different values of kernel function parameters were selected as determining which one provides better regression accuracy. The four kernel function parameters and the accompanying average estimation errors and correlation coefficients are represented in Table 5. Synthetically considering the regression performance and the kernel function parameter number, a peak shear strength of RVM model based on a Gaussian kernel function is established. The optimal value of the kernel function parameter $d$ is 52.43 .

5.2. Comparison with Existing Criteria. To certify the rationality of the proposed model, the two models developed by Grasselli and Egger [5] and Yang et al. [8] have been chosen for comparison.

$$
\begin{aligned}
& \text { Grasselli's model: } \tau_{p}=\left[1+\exp \left(-\frac{\theta_{\max }^{*} \sigma_{\mathrm{n}}}{9 A_{0} C \sigma_{\mathrm{t}}}\right)\right] \sigma_{\mathrm{n}} \tan \left[\varphi_{b}+\left(\frac{\theta_{\max }^{*}}{C}\right)^{1.18 \cos \beta}\right], \\
& \text { Yang's model: } \tau_{p}=\sigma_{\mathrm{n}} \tan \left[\varphi_{\mathrm{b}}+\frac{\theta_{\max }^{*}}{C^{0.45}} e^{\left(-\sigma_{\mathrm{n}} / \mathrm{JCS}\right) C^{0.75}}\right] .
\end{aligned}
$$

The 3D morphology parameters of the 50 rock joints are represented in Table 4 . The estimated results using equations (16) and (17), the RVM model results, and the measured peak shear strength are listed in Table 4. The prediction results of the peak shear strength of rock joints are compared with the measured data, as shown in Figures 4 and 5.

According to equation (9), the mean errors of the estimated value results calculated using Grasselli's model, Yang's model, and RVM model are 16.3\%, 8.9\%, and 15.4\%, respectively. Based on equation (11), the correlation values of the estimated value results calculated using Grasselli's model, Yang's model, and RVM model are 0.889, 0.940, and 0.938 , respectively. From the mean error and correlation coefficient analysis, the average estimation error values of the three models are less than $20 \%$ and the correlation coefficients are greater than 0.85 , which indicate that the three models were quite efficient to be used to predict the shear strength of rock joints. Moreover, the proposed model is more accurate than that of Grasselli's model and has almost equivalent precision to that of Yang's model. After analysis of the above average errors, the existent limitations of the three models should be pointed out. In Grasselli's and Yang's models, the function forms are complex. According to Grasselli's model (i.e., equation (14)), the ratio $\left(\theta_{\max }^{*} / C\right.$ ) was taken as a measure of joint surface roughness, but $C$ cannot be zero ( $C=0$ for saw-tooth joints). Yang's model is not fully explained on how to use the two parameters $\theta_{\max }^{*}$ and $C$ in combination, and $A_{0}$ is not even considered. Furthermore, Grasselli and Egger [5] and Yang et al. [8] deemed that the actual contact area was closely related with 


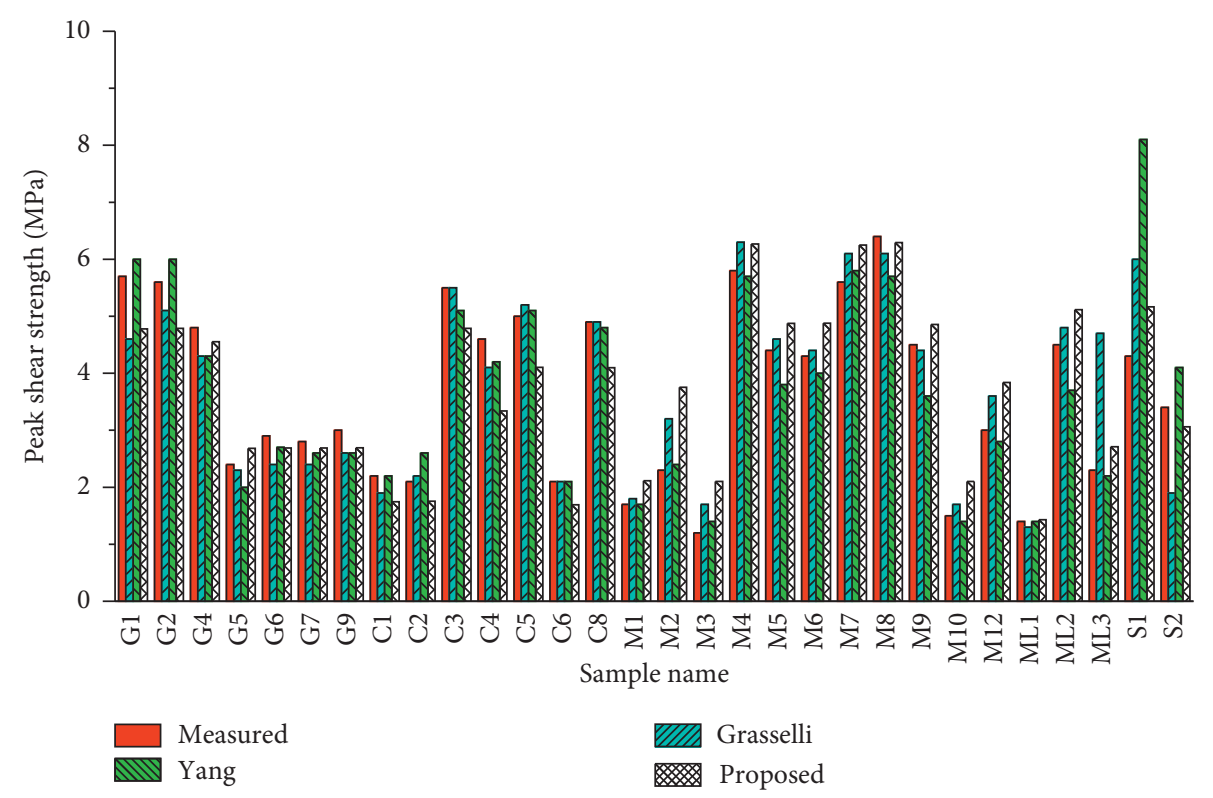

FIGURE 4: Measured peak shear strength of rock joints by Grasselli and Egger [5], which was calculated using Grasselli's model, Yang's model, and the proposed model.

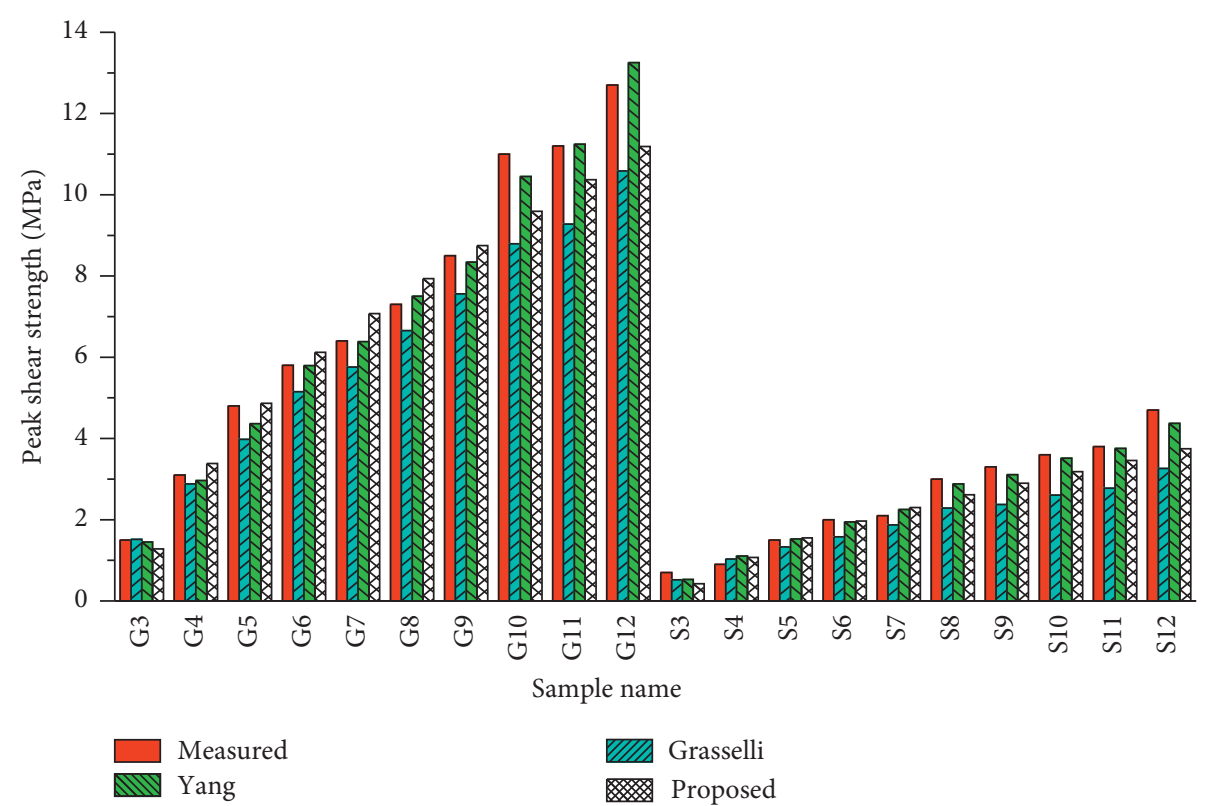

Figure 5: Measured peak shear strength of rock joints by Yang et al. [8], which was calculated using Grasselli's model, Yang's model, and the proposed model.

$\sigma_{\mathrm{n}} / \sigma_{\mathrm{t}}$ and $\sigma_{\mathrm{n}} / \sigma_{\mathrm{c}}$, respectively. Compared with Grasselli's and Yang's models, the proposed model was less complex for large samples and comprehensively considered many factors; in particular, the effect of compressive strength and tensile strength on the peak shear strength of rock joints was first investigated. However, the determination of kernel function parameter needs to be further improved and optimized.

In this study, the investigation is limited to the shear behavior of unfilled joints. Influencing factors, such as size of joint (scale effect), sampling interval, joint matching coefficient, and joint filling, should be further investigated. Although the proposed model has limitations, it is believed to be a novel research idea for assessing peak shear strength of rock joints.

\section{Conclusions}

The hybrid probabilistic regression assessment algorithm RVM was accustomed to identify the peak shear strength of the rock joint, with Gaussian kernel function being introduced to improve the prediction accuracy. The direct 
shear tests on joint specimens were conducted to train the new model, and its rationality on assessing the peak shear strength was also validated. Some concluding remarks are presented as follows:

(1) A novel intelligent peak shear strength model combined with RVM was supposed to assess the peak shear strength of rock joints, which can comprehensively consider the elements influencing the peak shear strength, such as normal stress, joint surface roughness, rock strength, and basic friction angle. The 36 natural granite joint specimens were accustomed to examine the suggested model, and the result reflects that the RVM model exhibits good training accuracy and high generalization capacity.

(2) Four types of kernel functions were investigated for their performance in regression accuracy in the RVM model. According to the regression performance and the kernel function parameter number, the Gaussian kernel function was determined to be the better one combined with the RVM model. The optimal value of the kernel function parameter $d$ is 52.43 .

(3) The peak shear model of Grasselli's and Yang's was chosen for comparison with the proposed model. Based on the 3D morphology parameters of 50 rock joints, the prediction results show that the proposed model can meet the accuracy requirements. In addition, the new model has less complexity and can take into account the effects of compressive strength and tensile strength on the peak shear strength of rock joints.

\section{Data Availability}

The data used to support the findings of this study are included within the article.

\section{Conflicts of Interest}

The authors declare no conflicts of interest.

\section{Acknowledgments}

The study was funded by the Natural Science Foundation of Zhejiang Province (no. LY18D020003) and the National Natural Science Foundation of China (nos. 41327001, 41572299, 41427802). This support was gratefully acknowledged.

\section{Supplementary Materials}

1. The file named topograph_3D is the code for the $3 \mathrm{D}$ parameter of $\theta_{\max }^{*} /(C+1)$. 2. The file named Data contains two sheets, one of which is the prediction of the shear strength, and the second is the comparison of the kernel functions. 3 . The file named $3 \mathrm{D}$ roughness parameter is the fitting curves of SJ3, SJ12, SJ21, and SJ30 for calculating the roughness parameter $\mathrm{C}$. 4 . The file named Comparation is the display of the shear strength prediction comparison with the model of Grasselli's and Yang's. (Supplementary Materials)

\section{References}

[1] D. Huang, C. Yang, B. Zeng, and G. Fu, "A copula-based method for estimating shear strength parameters of rock mass," Mathematical Problems in Engineering, vol. 2014, Article ID 693062, 11 pages, 2014.

[2] F. D. Patton, "Multiple modes of shear failure in rock," in Proceedings of 1st Congress of International Society for Rock Mechanics, pp. 509-513, Lisbon, Portugal, October 1966.

[3] N. Barton, "Review of a new shear-strength criterion for rock joints," Engineering Geology, vol. 7, no. 4, pp. 287-332, 1973.

[4] P. H. S. W. Kulatilake, G. Shou, T. H. Huang, and R. M. Morgan, "New peak shear strength criteria for anisotropic rock joints," International Journal of Rock Mechanics and Mining Sciences \& Geomechanics Abstracts, vol. 32, no. 7, pp. 673-697, 1995.

[5] G. Grasselli and P. Egger, "Constitutive law for the shear strength of rock joints based on three-dimensional surface parameters," International Journal of Rock Mechanics and Mining Sciences, vol. 40, no. 1, pp. 25-40, 2003.

[6] C.-C. Xia, Z.-C. Tang, W.-M. Xiao, and Y.-L. Song, "New peak shear strength criterion of rock joints based on quantified surface description," Rock Mechanics and Rock Engineering, vol. 47, no. 2, pp. 387-400, 2014.

[7] Z. C. Tang and L. N. Y. Wong, "New criterion for evaluating the peak shear strength of rock joints under different contact states," Rock Mechanics and Rock Engineering, vol. 49, no. 4, pp. 1191-1199, 2016.

[8] J. Yang, G. Rong, D. Hou, J. Peng, and C. Zhou, "Experimental study on peak shear strength criterion for rock joints," Rock Mechanics and Rock Engineering, vol. 49, no. 3, pp. 821-835, 2016.

[9] C. C. Garcia-Fernandez, C. Gonzalez-Nicieza, M. I. AlvarezFernandez, and R. A. Gutierrez-Moizant, "New methodology for estimating the shear strength of layering in slate by using the Brazilian test," Bulletin of Engineering Geology and the Environment, vol. 78, no. 4, pp. 2283-2297, 2019.

[10] J. P. Seidel and C. M. Haberfield, "The application of energy principles to the determination of the sliding resistance of rock joints," Rock Mechanics and Rock Engineering, vol. 28, no. 4, pp. 221-226, 1995.

[11] F. Lanaro and O. Stephansson, "A unified model for characterisation and mechanical behaviour of rock fractures," Thermo-Hydro-Mechanical Coupling in Fractured Rock, vol. 160, no. 5-6, pp. 989-998, 2003.

[12] Z. C. Tang, Y. Y. Jiao, L. N. Y. Wong, and X. C. Wang, "Choosing appropriate parameters for developing empirical shear strength criterion of rock joint: review and new insights," Rock Mechanics and Rock Engineering, vol. 49, no. 11, pp. 4479-4490, 2016.

[13] J. Ye, R. Yong, Q.-F. Liang, M. Huang, and S.-G. Du, "Neutrosophic functions of the joint roughness coefficient and the shear strength: a case study from the pyroclastic rock mass in Shaoxing city, China," Mathematical Problems in Engineering, vol. 2016, Article ID 4825709, 9 pages, 2016.

[14] H. Lin, S. Xie, R. Yong, Y. Chen, and S. Du, "An empirical statistical constitutive relationship for rock joint shearing considering scale effect," Comptes Rendus Mécanique, vol. 347, no. 8, pp. 561-575, 2019.

[15] H. Lin, H. Yang, Y. Wang, Y. Zhao, and R. Cao, "Determination of the stress field and crack initiation angle of an 
open flaw tip under uniaxial compression," Theoretical and Applied Fracture Mechanics, vol. 104, Article ID 102358, 2019.

[16] I. Yilmaz and A. Yuksek, "An example of artificial neural network (ANN) application for indirect estimation of rock parameters," Rock Mechanics and Rock Engineering, vol. 41, no. 5, pp. 781-795, 2008.

[17] K. Sarkar, A. Tiwary, and T. N. Singh, "Estimation of strength parameters of rock using artificial neural networks," Bulletin of Engineering Geology and the Environment, vol. 69, no. 4, pp. 599-606, 2010.

[18] N. Ceryan, U. Okkan, and A. Kesimal, "Prediction of unconfined compressive strength of carbonate rocks using artificial neural networks," Environmental Earth Sciences, vol. 68, no. 3, pp. 807-819, 2013.

[19] E. Momeni, D. Jahed Armaghani, M. Hajihassani, and M. F. Mohd Amin, "Prediction of uniaxial compressive strength of rock samples using hybrid particle swarm optimization-based artificial neural networks," Measurement, vol. 60 , pp. 50-63, 2015.

[20] D. J. Armaghani, E. T. Mohamad, E. Momeni, M. Monjezi, and M. S. Narayanasamy, "Prediction of the strength and elasticity modulus of granite through an expert artificial neural network," Arabian Journal of Geosciences, vol. 9, no. 1, p. 48, 2016.

[21] L. K. Sharma, V. Vishal, and T. N. Singh, "Developing novel models using neural networks and fuzzy systems for the prediction of strength of rocks from key geomechanical properties," Measurement, vol. 102, pp. 158-169, 2017.

[22] V. N. Vapnik, Statistical Learning Theory, Wiley, New York, NY, USA, 1998.

[23] D. Park and L. R. Rilett, "Forecasting freeway link travel times with a multilayer feed forward neural network," ComputerAided Civil and Infrastructure Engineering Journal, vol. 14, no. 5, pp. 357-367, 1999.

[24] P. Samui, T. Lansivaara, and D. Kim, "Utilization relevance vector machine for slope reliability analysis," Applied Soft Computing, vol. 11, no. 5, pp. 4036-4040, 2011.

[25] M. Marjanović, M. Kovačević, B. Bajat, and V. Voženílek, "Landslide susceptibility assessment using SVM machine learning algorithm," Engineering Geology, vol. 123, no. 3, pp. 225-234, 2011.

[26] X. Qian, J. Chen, L.-J. Xiang, L. Xiang, W. Zhang, and C. Niu, "A novel hybrid KPCA and SVM with PSO model for identifying debris flow hazard degree: a case study in Southwest China," Environmental Earth Sciences, vol. 75, no. 11, p. 991, 2016.

[27] R. Gholami, V. Rasouli, and A. Alimoradi, "Improved RMR rock mass classification using artificial intelligence algorithms," Rock Mechanics and Rock Engineering, vol. 46, no. 5, pp. 1199-1209, 2013.

[28] M. E. Tipping, "Sparse Bayesian learning and the relevance vector machine," Journal of Machine Learning Research, vol. 1, pp. 1211-1244, 2001.

[29] M. E. Tipping, "Bayesian inference: an introduction to principles and practice in machine learning," in Advanced Lectures on Machine Learning, pp. 41-46, Springer, Berlin, Germany, 2004.

[30] P. Samui and B. Dixon, "Application of support vector machine and relevance vector machine to determine evaporative losses in reservoirs," Hydrological Processes, vol. 26, no. 9, pp. 1361-1369, 2012.

[31] W. Hatheway, "The complete ISRM suggested methods for rock characterization, testing and monitoring: 1974-2006,"
Environmental and Engineering Geoscience, vol. 15, no. 1, pp. 47-48, 2009.

[32] C. C. Xia, X. Qian, P. Lin, W. M. Xiao, and Y. Gui, "Experimental investigation of nonlinear flow characteristics of real rock joints under different contact conditions," Journal of Hydraulic Engineering, vol. 143, no. 3, Article ID 04016090, 2017.

[33] B. S. A. Tatone and G. Grasselli, "A method to evaluate the three-dimensional roughness of fracture surfaces in brittle geomaterials," Review of Scientific Instruments, vol. 80, no. 12, Article ID 125110, 2009.

[34] N. Barton and V. Choubey, "The shear strength of rock joints in theory and practice," Rock Mechanics Felsmechanik Mecanique des Roches, vol. 10, no. 1-2, pp. 1-54, 1977.

[35] I. W. Yeo, M. H. de Freitas, and R. W. Zimmerman, "Effect of shear displacement on the aperture and permeability of a rock fracture," International Journal of Rock Mechanics and Mining Sciences, vol. 35, no. 8, pp. 1051-1070, 1998.

[36] G. Grasselli, "Manuel rocha medal recipient shear strength of rock joints based on quantified surface description," Rock Mechanics and Rock Engineering, vol. 39, no. 4, pp. 295-314, 2006.

[37] Z.-C. Tang, Q.-S. Liu, and J.-H. Huang, "New criterion for rock joints based on three-dimensional roughness parameters," Journal of Central South University, vol. 21, no. 12, pp. 4653-4659, 2014.

[38] G. Grasselli, J. Wirth, and P. Egger, "Quantitative three-dimensional description of a rough surface and parameter evolution with shearing," International Journal of Rock Mechanics and Mining Sciences, vol. 39, no. 6, pp. 789-800, 2002.

[39] S. Saeb and B. Amadei, "Modelling rock joints under shear and normal loading," International Journal of Rock Mechanics and Mining Sciences \& Geomechanics Abstracts, vol. 29, no. 3, pp. 267-278, 1992.

[40] F. Johansson and H. Stille, "A conceptual model for the peak shear strength of fresh and unweathered rock joints," International Journal of Rock Mechanics and Mining Sciences, vol. 69, pp. 31-38, 2014.

[41] Q. Liu, Y. Tian, P. Ji, and H. Ma, "Experimental investigation of the peak shear strength criterion based on three-dimensional surface description," Rock Mechanics and Rock Engineering, vol. 51, no. 4, pp. 1005-1025, 2018.

[42] M. S. Asadi, V. Rasouli, and G. Barla, "A laboratory shear cell used for simulation of shear strength and asperity degradation of rough rock fractures," Rock Mechanics and Rock Engineering, vol. 46, no. 4, pp. 683-699, 2013.

[43] A. H. Ghazvinian, M. J. Azinfar, and R. Geranmayeh Vaneghi, "Importance of tensile strength on the shear behavior of discontinuities," Rock Mechanics and Rock Engineering, vol. 45, no. 3, pp. 349-359, 2012.

[44] Y. Tian, Q. Liu, D. Liu, Y. Kang, P. Deng, and F. He, "Updates to grasselli's peak shear strength model," Rock Mechanics and Rock Engineering, vol. 51, no. 7, pp. 2115-2133, 2018.

[45] G. Grasselli, Shear strength of rock joints based on quantified surface description, Swiss Federal Institute of Technology, Zurich, Switzerland, Ph.D. dissertation, 2001.

[46] F. Kuang, W. Xu, and S. Zhang, "A novel hybrid KPCA and SVM with GA model for intrusion detection," Applied Soft Computing, vol. 18, pp. 178-184, 2014. 


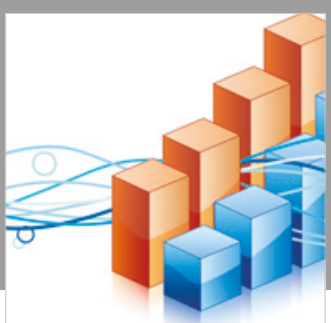

Advances in

Operations Research

\section{-n-m}
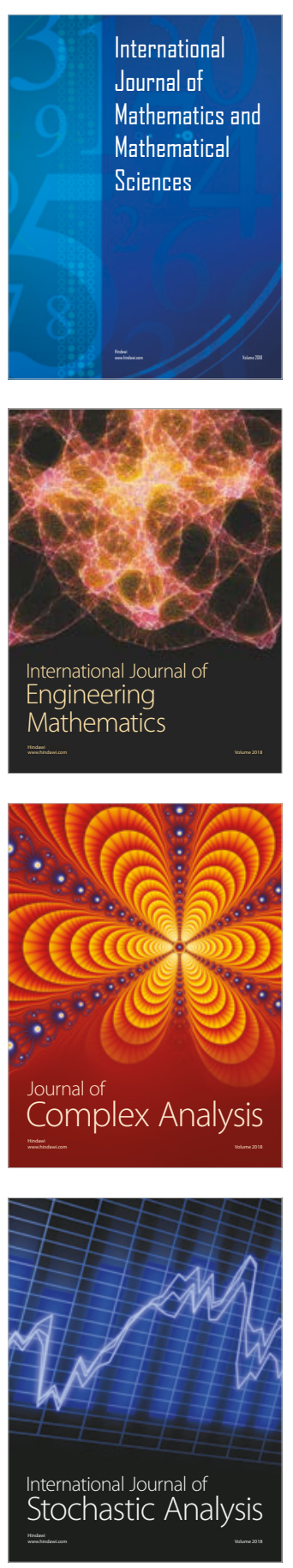
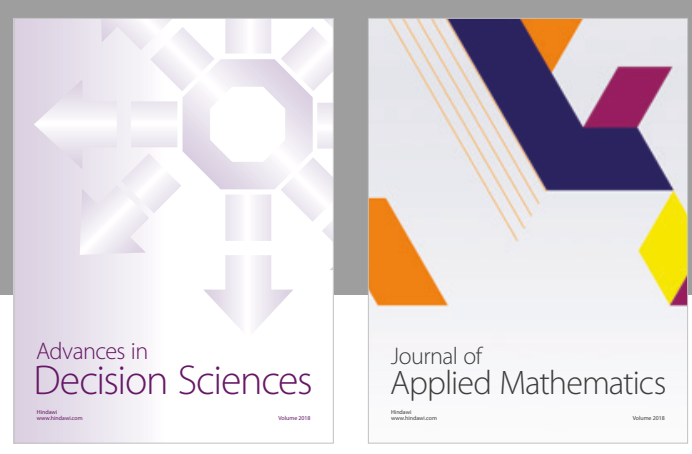

Journal of

Applied Mathematics
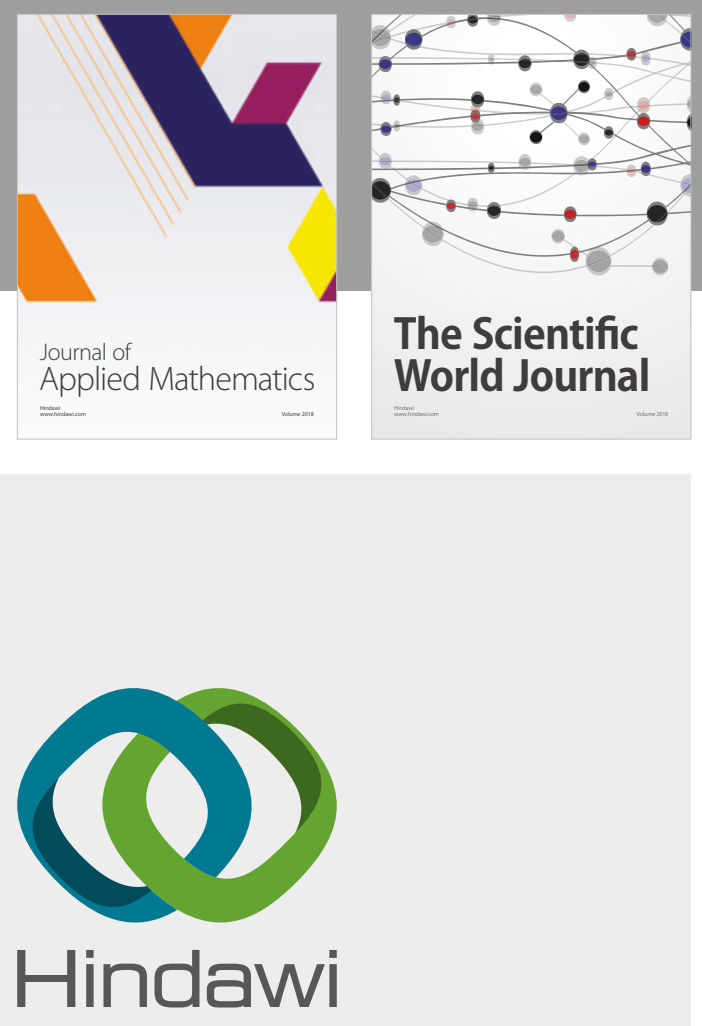

Submit your manuscripts at

www.hindawi.com

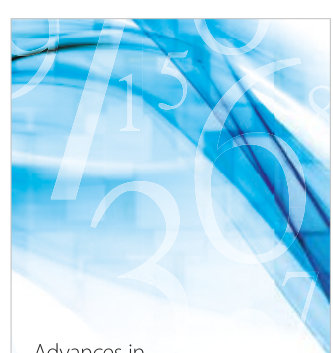

Advances in
Numerical Analysis
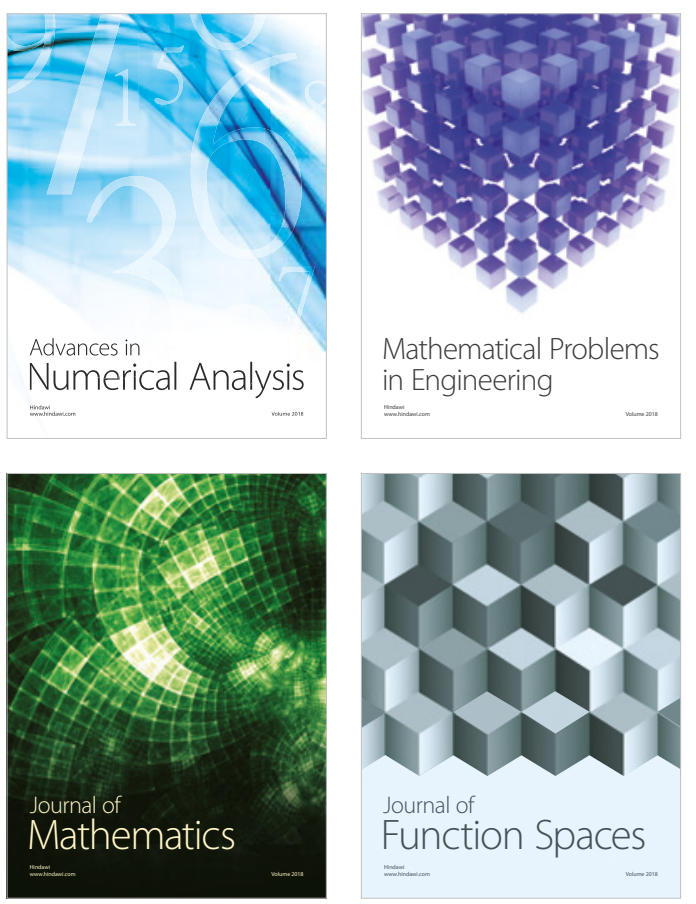

Mathematical Problems in Engineering

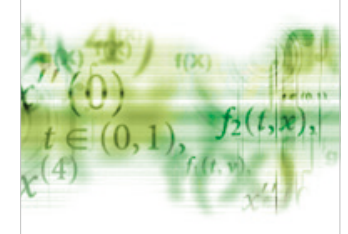

International Journal of

Differential Equations

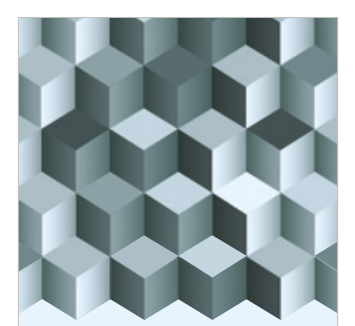

Journal of

Function Spaces

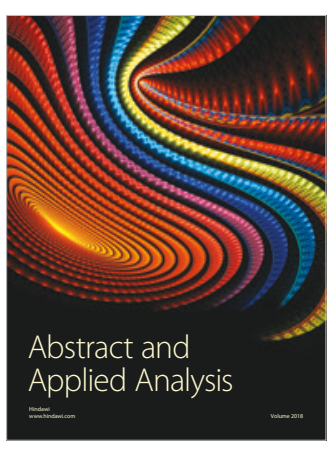

The Scientific

World Journal

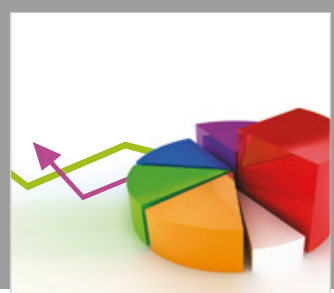

Journal of

Probability and Statistics
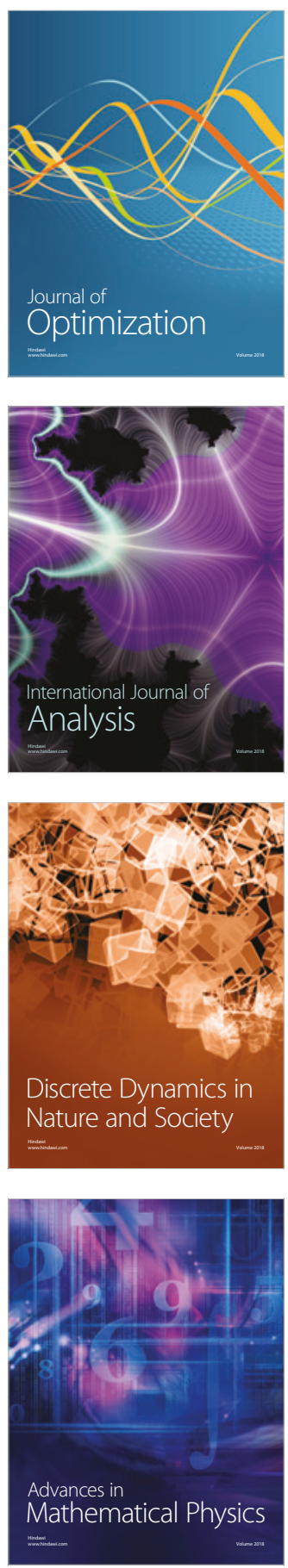